\title{
$\mathrm{P} H \mathbf{8 8}$ entrevista
}

\section{Dominique Perrault: "El sector público sigue manteniendo el liderazgo político en la patrimonialización de la ciudad contemporánea, a pesar de la falta de inversión"}

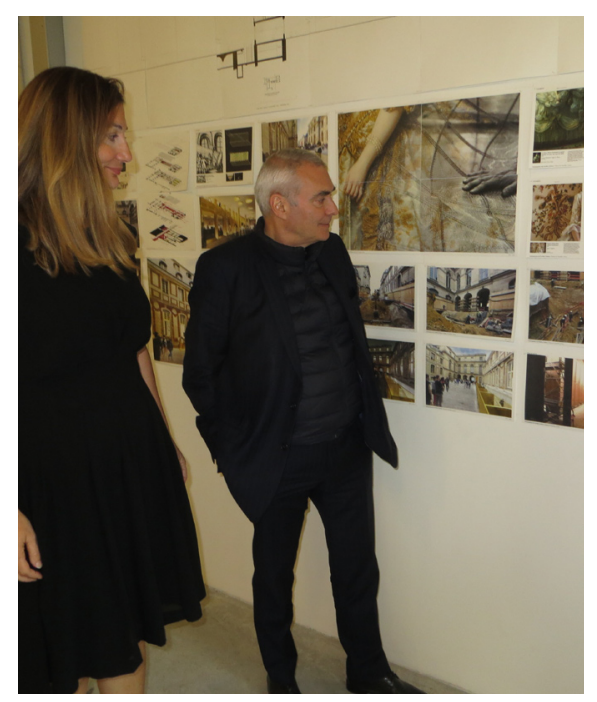

Dominique Perrault, al terminar la entrevista, visitando la exposición Groundscape. Le acompaña M. ${ }^{\text {a }}$ Teresa Pérez Cano | foto Charlotte Jean
URL de la contribución <www.iaph.es/revistaph/index.php/revistaph/article/view/3689>

Dominique Perrault (Clermont-Ferrand, 1953) es arquitecto diplomado por la Escuela Nacional Superior de Bellas Artes de París. Completó su formación pluridisciplinar en otras célebres instituciones parisinas: Certificado de Estudios Superiores en Urbanismo por la Escuela de Ingenieros de Caminos (miembro de la Sociedad Francesa de Urbanistas) y Diploma de Estudios Avanzados en Historia, por la Escuela de Altos Estudios en Ciencias Sociales.

La apertura de su estudio DPA en París (1981) significa el arranque de una carrera bien celebrada. Su obra, diseminada por numerosos países, incluye referentes como la nueva Biblioteca Nacional de Francia, transformadora del paisaje ribereño del Sena, velódromo y piscina olímpica (Berlín), plaza Garibaldi (Nápoles), Universidad Femenina Ewha (Seúl), centro de tenis Caja Mágica (Madrid), Tribunal Europeo de Justicia (Luxemburgo)...

Más de una treintena de exposiciones han ilustrado su producción. En nuestro país, en la Fundación ICO (Madrid, 2009).

Además de numerosos artículos y referencias sobre su labor en proyectos concretos, más de cuarenta libros, catálogos de exposiciones y revistas recogen monográficamente su extensa producción arquitectónica y su actividad como diseñador.

Ha recibido cerca de cuarenta premios y reconocimientos. Entre ellos el Nacional de Arquitectura de Francia, el Premio Europeo de Arquitectura Mies van der Rohe, el Premio del American Institute of Architects, la Medalla de Oro de la Academia de la Arquitectura francesa por el conjunto de su obra, sucesivamente caballero y oficial de la Legión de Honor, etc. Recientemente le ha sido concedido el prestigioso Premium Imperiale 2015 (edición 27.a) que otorga la familia imperial japonesa en nombre de la Asociación de Arte de Japón.

Ha concedido esta entrevista a revista $\mathrm{PH}$ para hablar de sus últimos trabajos relacionados con el patrimonio y su visión personal del mismo desde su posición decididamente contemporánea. Fue realizada por los arquitectos Eduardo Mosquera Adell y María Teresa Pérez Cano, respectivamente profesores de Historia, Teoría y Composición Arquitectónicas y de Urbanística y Ordenación del Territorio en la Universidad de Sevilla, y docentes del Máster en Arquitectura y Patrimonio Histórico. 
Dominique Perrault nos recibe en su estudio de la rue Bouvier, en el $11 .^{\circ}$ distrito parisino. Es el último día de julio y una intensa actividad llena esta antigua nave industrial. Una fábrica rehabilitada donde tiene su sede principal Dominique Perrault Architecture. Nos encontramos con maquetas, prototipos de mobiliario, luminarias, mallas y sobre todo con un gran equipo humano de muy diversa procedencia, en general joven, que se afana con los diversos trabajos que simultanea el estudio. Un particular sentido del orden convierte en productivo este prolijo escenario, que tiene como colofón una sala de exposiciones de trescientos metros cuadrados, en el fondo de la planta baja de la nave. La entrevista tiene lugar en la sala de reuniones próxima al espacio expositivo, al que acudiremos finalizando la conversación. La exposición Groundscape, casi lista y realmente un elemento de trabajo de carácter privado, semanas después recibió la visita de François Hollande.

Deseamos adentrarnos en su posición como arquitecto surgido de la tradición moderna ante el patrimonio, siendo un factor determinante de buena parte de su obra reciente.

Podemos hablar para ello de tres ejemplos, uno de los siglos XVII y XVIII, otro del XIX y un tercer ejemplo del $X X$. Sucesivamente, Versalles, la Central de Correos del Louvre y las torres del Pont de Sèvres.

revista ph: ¿Cómo afronta una obra de rehabilitación en uno de los monumentos y jardines más visitados del mundo?

Versalles es un poco como el proyecto del Louvre en París, es decir, la idea de que el público entre y salga por el mismo sitio. En el Louvre de Pei esta era evidentemente una cuestión clave, porque el edificio preexistente era muy grande. Así, se construirá la pirámide, ahora convertida en el corazón del Louvre. Un punto central a partir del cual se puede circular pero donde hay varias posibilidades para salir. En Versalles el caso es un poco diferente, hay que entrar en el palacio, visitarlo y volver para salir por el mismo sitio. No es un museo como el Louvre, en Versalles existe un recorrido completo de visita.
Hemos hecho un trabajo para acoger a varios millones de visitantes, pero para que salgan por el mismo sitio. Hemos elegido el ala izquierda -mirando al palacio- ahora libre y que había sido ocupada por la administración.

revista ph: ¿Cómo cree que cohabita la arquitectura de factura histórica con la articulación de algo que sea más que un programa funcional?

El Pabellón Dufour de Versalles es un trabajo bastante particular, porque es una obra que interesa como intervención relacionada con el suelo, particularmente con el subsuelo de este edificio y también del Patio de los Príncipes. Se desarrolla así un proyecto que no es solo sobre el pabellón, sino que también lo es sobre sus espacios exteriores. Esta estrategia nos posibilita ampliar la superficie del Palacio de Versalles de un nuevo modo. De hecho, estos metros cuadrados van a conectar espacios patrimoniales entre sí, y finalmente van a revitalizar ese patrimonio, relacionándolo con usos contemporáneos.

Es una intervención sobre el suelo, en el suelo. Pero también supone la creación de grandes escaleras de salida para el público en dirección a los jardines, pues tras la visita al palacio se puede salir seguidamente a ellos. La posición de estas escaleras es extremadamente simbólica y funcional, por supuesto, ya que será una obra del siglo XXI, situada entre la llamada "ala vieja" que se construyó en el siglo XVII, y el Pabellón Dufour, obra del XVIII. De este modo, se ha creado un nexo entre diferentes épocas, con la disposición de un sistema de acogida en una gran galería, que recibe al público en planta baja. A continuación, éste efectúa su visita y vuelve, para salir desde el subsuelo, por las escaleras.

Habrá una librería de los Museos Nacionales, así como obras de arte del Museo de Versalles, del propio palacio y también contemporáneas.

No es un espacio nuevo en relación a Versalles; es la primera sala que el público va a visitar. Todo un trabajo de integración de esta zona, que era administrativa y que ahora se convierte en pública. Insisto, no es un espacio nuevo, en términos de uso, y eso lo diferencia del ejemplo de la pirámide del Louvre. 


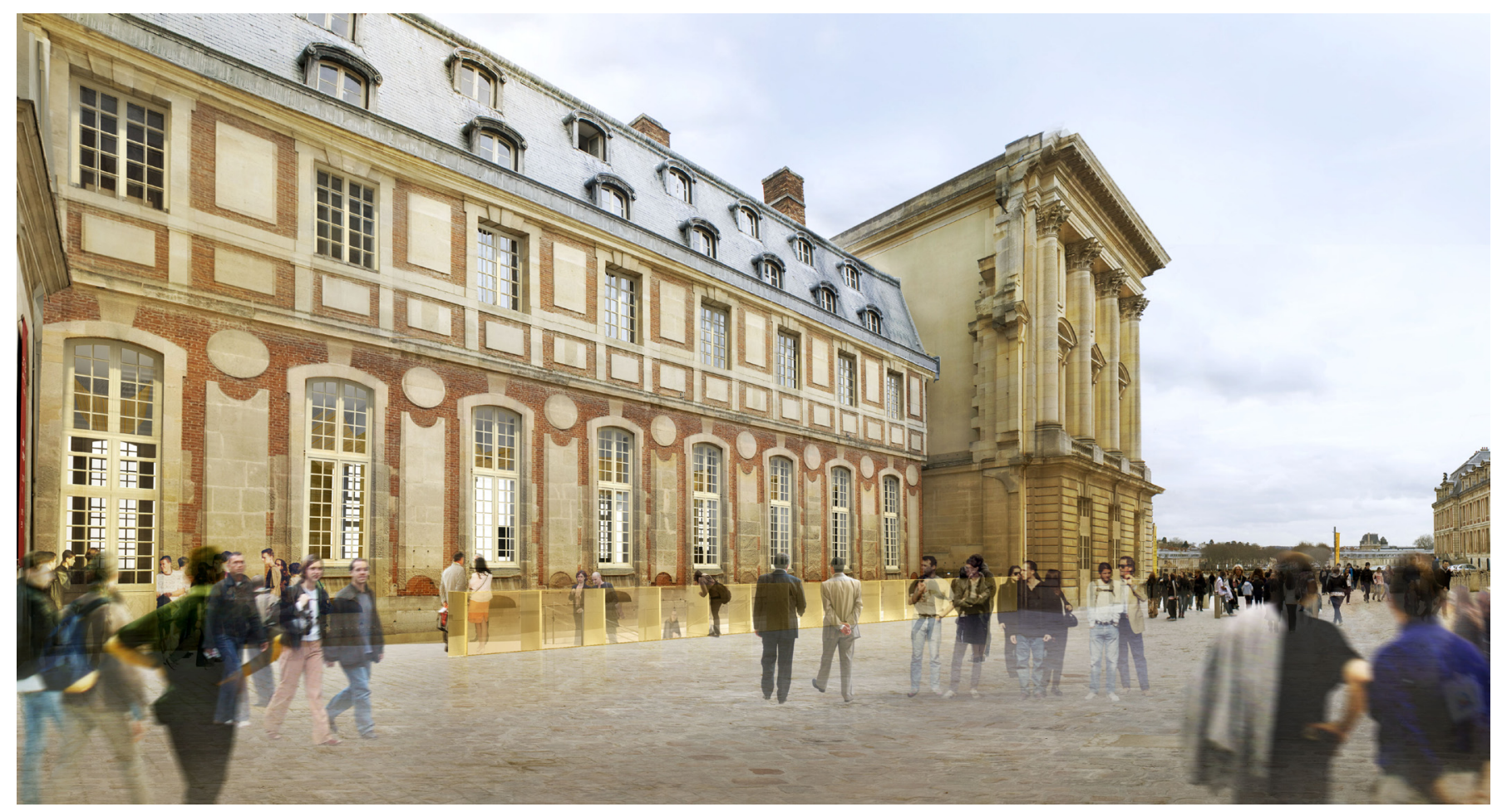

Acondicionamiento del Pabellón Dufour y Patio de los Príncipes. Palacio de Versalles (2011-2015) | foto @ Dominique Perrault Architecte / Adagp

En primera planta se va a instalar un café restaurante y bajo la cubierta un pequeño auditorio. Un elemento muy interesante, en referencia a la vida de lo patrimonial, porque este Pabellón Dufour puede usarse de forma autónoma respecto al palacio. Es decir, que se puede compatibilizar la organización de desayunos, proyecciones de películas, conferencias, privatizar ocasionalmente el restaurante... Puede dársele vida al pabellón tras los espectáculos de ópera, los grandes shows de luz y sonido... Por tanto, es un pabellón que va a vivir otro ritmo que el propio palacio.

revista ph: ¿Existe un propósito declarado de amplificar su resonancia, su presencia a partir de las referencias de Versalles empleadas en los recursos de diseño?

Es un elemento muy interesante, nuevo en este espacio. Hemos efectuado con Gaëlle Lauriot-Prévost una labor de colaboración, un gran trabajo de diseño, especialmente sobre las luminarias, tomando como referencia los lustres y brillos al estilo de Versalles. Todo en metal: el suelo, los techos en trenzados de malla metá- lica, las luminarias. También hay revestimientos en latón que marcan la presencia de muros históricos.

Se trata de una interpretación de Versalles en metal. Es bastante divertido desde el punto de vista visual y muy interesante desde el punto de vista táctil. Porque se aprecia que el metal es algo muy sensual, como un tisú, con el mismo detalle que un encaje, en una labor de diseño de moda, aunque pueda pensarse que el metal es siempre frío.

revista ph: ¿De qué modo responde usted ante la intervención en una arquitectura decimonónica, para enriquecer nuestros modos de vida contemporáneos en el seno de la ciudad histórica que demanda una renovación?

Si hablamos del siglo XIX, tenemos el trabajo de la central de Correos del Louvre. Julien Guadet realizó este edificio en 1888. Es un edificio manifiesto, pues Guadet era un profesor de Arquitectura muy conocido. Escribía libros. Y es el único edificio que llegó a construir, una cuestión que resulta claramente interesante. 


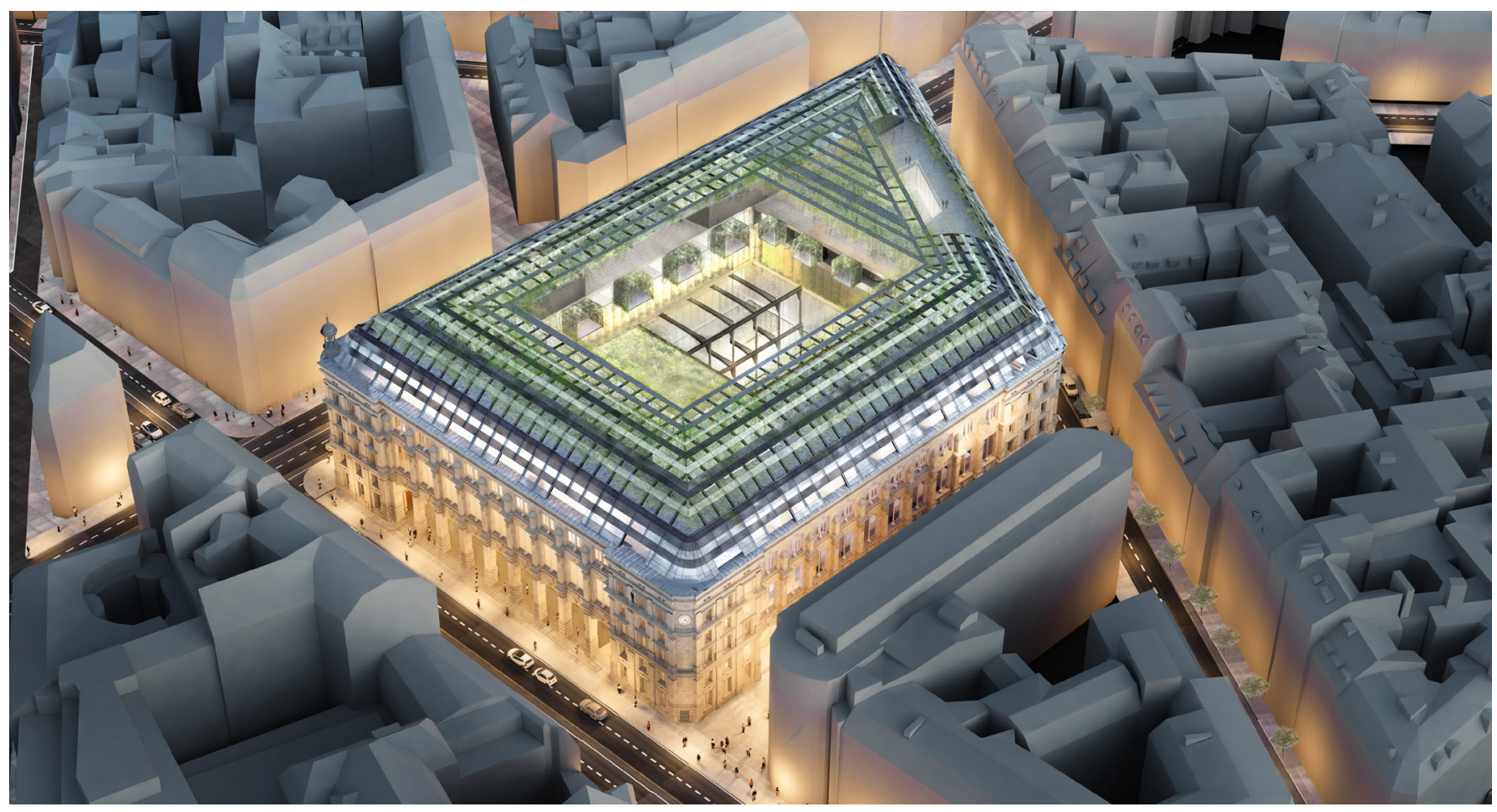

Reestructuración del edificio de Correos del Louvre, París (2012-2018) | foto @ Dominique Perrault Architecte / Adagp

Se trata de un monumento del siglo XIX, en el que hay que gestionar una arquitectura un tanto industrial... pero que tiene una concepción monumental. Además, es un edificio que no tiene la dimensión de París, en el sentido de cómo se le percibe en el tejido urbano parisino, que está compuesto de pequeños edificios que se suceden y crean manzanas. De hecho, se trata de un edificio que en sí mismo es una manzana.

De forma que es una morfología como la de Manhattan, del Soho. Las manzanas del Soho son un edificio, con la misma tipología: una fachada de piedra muy potente, muy arquitectónica y monumental. Y, después, un interior de metal, una estructura metálica, con la idea de monumentalizar la industria, para que se pueda aceptar en armonía con la ciudad. Insisto en que es una idea muy atractiva.

revista ph: ¿Su arquitectura se muestra diferente ante un edificio existente, en un entorno con trazas históricas profundamente enraizadas en la cultura francesa y europea?
Aplicamos la idea completamente contemporánea de desarrollar la evolución del edificio, desde la flexibilidad, digamos desde una reversibilidad. Manejamos de algún modo un concepto muy actual. Es un desafío muy importante para París, pues será la primera realización de una manzana que va a vivirse las 24 horas del día con usos mixtos. Lo que no existe en París, pero sí en otras ciudades como Londres, Nueva York, Ámsterdam, etc. Pero en París va a ser la primera vez.

Abrirá día y noche. También tendrá funciones operacionales de correos, pero obviamente mucho más informatizadas que ahora. Habrá comercios, también espacios de coworking, vinculados a la vida del barrio, oficinas, una pequeña comisaría, una guardería, que estará también abierta día y noche. Además, un hotel que, evidentemente, estará abierto día y noche. Esto nos va a posibilitar reconstruir toda la cubierta en el volumen de Julien Guadet, con este hotel, pero también definiendo una gran terraza, a la cual se podrá lógicamente acceder. Desde allí se tendrá una extraordinaria vista de la ciudad de París. 
La terraza estará de algún modo relacionada con la del Beaubourg, el Centro Pompidou. Cuando se sube a lo alto del Pompidou, se está en el techo de París. Se ve París, aunque estamos realmente en el nivel de las cubiertas y tejados. El Pompidou es un poco más alto, pero Correos será... como si fuera un gran balcón de tu casa, con visuales hacia el este y el oeste de París.

revista ph: Determinados conceptos establecidos más recientemente, nuevos paradigmas emergentes, pueden enriquecer su posición ante el hecho arquitectónico mediante el patrimonio. ¿Cómo proyecta esta coexistencia?

El proyecto es un trabajo de revelación de este edificio. Es decir, como en el caso de Versalles, no es una restitución, es una investigación sobre cómo se revela el patrimonio. Se trata de algo un poco diferente, no busca la restitución histórica con una fecha concreta, más bien se trata de un trabajo singular, de la puesta de manifiesto del concepto patrimonial del edificio. La intervención posibilita hacerlo vivir, revitalizar precisamente esta estructura, sin quedarnos presos en términos de mera restitución de techos, muros, molduras. Se afronta con el proyecto la introducción de usos de hoy, de una economía real, que posibilita dar vida al edificio, de mantenerlo.

Se han empezado a tratar los techos pues en ellos se han encontrado pinturas del siglo XIX, que se van a poner en valor. Se aborda lógicamente la protección, la conservación de la fachada, de la piedra, de la estructura metálica y también se asumen los usos históricos del edificio. Puesto que la histórica oficina de correos va a reencontrar su lugar allí.

Hemos comentado proyectos que son discretos, pero cada uno lo es de diferente manera. En Versalles se construye la base y el nivel alto del edificio. Correos, la Poste, es un trabajo de interpretación, únicamente en algunas partes de la fachada. Evidentemente se utiliza la estructura metálica del interior para recomponer espacios de luz natural y al aire libre.

Pero no se está prisionero del patrimonio, más bien es un trabajo de diálogo, de cambio, de respeto. También lo es de revelación de estos lugares, para que se abran a usos más diversos y a públicos más amplios.

revista ph: Las ciudades han evolucionado experimentando notables cambios en lo que fueron sus periferias. ¿Cuál es el planteamiento de la rehabilitación de un edificio del siglo $X X$ en ese escenario como es el caso de las torres del Pont de Sèvres?

Pensemos que estamos en los años 70, tras la reconstrucción de la Segunda Guerra Mundial en Francia, cuando son frecuentes proyectos de gran dimensión, con una elevada densidad. Hoy nos interesa esta cualidad, porque en los 70 el lugar de estos proyectos estaba lejos del centro de la ciudad. Las ciudades han crecido y las grandes ciudades se han convertido en metrópolis.

Este proyecto -que en los años 70 era periferia- ahora se encuentra en plena ciudad, y en general muy bien conectado por los transportes públicos. Entonces, lo que estaba lejos hace cuarenta años, hoy está a nuestras puertas. Así, el valor de este proyecto, desde el punto de vista social y económico, se ha vuelto muy importante y positivo.

El proyecto de rehabilitación de las torres del Pont de Sèvres interviene en una montaña de hexágonos, una concreción un tanto basáltica, como si nos encontráramos con una geografía. Y luego está la densidad..., hoy no somos capaces de construir edificios tan densos con las reglas del urbanismo actual. Eso significa que la rehabilitación de este conjunto arquitectónico se convierte en algo muy viable. Son muchos metros cuadrados, está bien situado, el entorno del edificio tiene muchos servicios..., de modo que la intervención es posible.

revista ph: ¿Cómo se trata esa densidad? ¿existe un nuevo gradiente entre las torres rehabilitadas y su intersección con la ciudad?

La alta densidad nos permite no construir más, lo que da pie a una calidad ambiental de sus arquitecturas, a un nuevo confort. Es decir, que cuando se elimina el amianto, el plomo y todos los productos tóxicos de los años 70 , cuando se instala el aislamiento y también sis- 


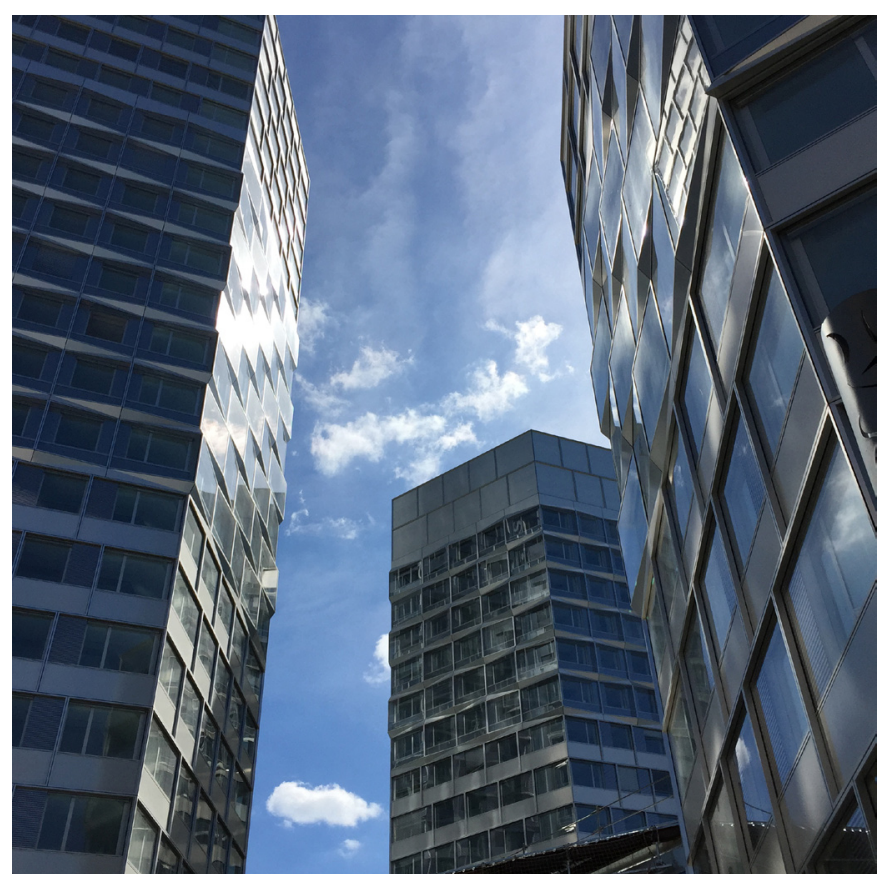

Rehabilitación de las torres del Pont de Sèvres, Boulogne-Billancourt (20072015) | foto (c) Dominique Perrault Architecte / Adagp

temas técnicos más eficientes tenemos, por tanto, la parte más bien energética. Pero también a las torres del Pont de Sèvres se le van a recuperar $5.000 \mathrm{~m}^{2}$, importantes, al pie del edificio. Se va a crear vida, servicios, pasajes cubiertos, espacios compartidos.

Por consiguiente, a este edificio, que es muy duro en la relación vertical y horizontal, le nace una nueva horizontalidad, en la cual estas torres van a encontrar sus raíces. Se trata, en cierto modo, de un trabajo de enraizamiento de estos conjuntos en el tejido urbano actual.

revista ph: ¿No participan todos los proyectos comentados de una estrategia común?

Es cierto para Versalles. También para Correos del Louvre, donde el enraizamiento implica la apertura de esta manzana industrial a todo el barrio, pues se convierte en una manzana urbana, con pasajes, como los que son tan frecuentes en los distritos $1 .^{\circ}$ y $2 .^{\circ}$ de París, que son muy hermosos. Realmente es la tipología de este barrio la que se va a enraizar y gestionar en términos de red.
Y lo mismo para las torres del Pont de Sèvres. Se va a crear una red que va a permitir pasar por debajo y a través de ellas, y que esta edificación no sea cerrada: crear focos en la circulación y en los intercambios urbanos.

revista ph: ¿Y entonces, dónde queda el concepto de calle y de lo urbano?

Realmente, aparece el cuestionamiento de una cierta idea de la morfología de la ciudad clásica tradicional, es decir, de la discusión acerca de la calle. No se afirma que la calle vaya a desaparecer, pero comenzamos a situar sistemas que son más complejos y que no se reducen a dos fachadas, dos aceras y una calzada, incluso aunque haya bellos árboles y vías secundarias. No es en absoluto intencional contra la calle, tal como se ha diseñado. Se trata más bien de evolucionar la noción de calle, que ya no es tanto ese espacio limitado, sino que se prolonga en el interior de los edificios, de las manzanas, algo completamente contemporáneo, y que acompaña -yo diría- a una forma de desaparición de un determinado clasicismo, y de la urbe, la ciudad, el urbanismo, lo urbano y la arquitectura.

revista ph: ¿Qué características tienen entonces la arquitectura, la ciudad y el paisaje que responden a los desafíos del patrimonio de nuestro tiempo?

Nos encontramos más bien en una transformación muy importante, que nos traslada a la historia y la geografía y la ciudad, en particular, desaparece; por tanto se convierte en metrópolis y por ello se convierte en territorio. La arquitectura ya no permanece con el mismo estatus, ya no puede permanecer inmóvil y representada de manera frontal. Se convierte en realidad en sistema, en red, y ya no puede obstaculizar, no puede comportarse como un muro: con el dentro, el fuera, la mirada..., es diferente.

Es cierto para el tejido urbano, y plantea una cuestión totalmente apasionante, en términos de percepción, también de búsqueda, de desarrollo de edificios y de ciudades que son completamente nuevas. Con una ruta, un elemento de explicación, por el que la ciudad era la marca de la conquista de la humanidad. Cuando el 
humanista se constituyó, creó ciudades y, tras las conquistas, lo hizo en otros continentes.

Hoy el planeta se conoce perfectamente, y la geografía ya no tiene conquistas como antes. La humanidad se encuentra por primera vez en un mundo terminado, lo que modifica nuestra mirada, nuestra percepción. Y no es por azar si la dimensión material de las redes se muestra, pues son actualmente el único espacio de expansión de la humanidad. Así, la ciudad desaparece y la metrópolis es la única posibilidad con la conquista del territorio. Lo que plantea cuestiones y trae reflexiones absolutamente apasionantes, en relación al patrimonio, ya que hasta el Milenio -los años 2000- todo lo que el hombre ha conocido es patrimonial, por definición, porque está terminado.

Si pensamos en vivir, como en una estampa o foto fija, un modelo de desarrollo social para la humanidad, el hecho puede resultar extremadamente grato, pero no siempre responde a las necesidades actuales. No quiere decir que haya que hacer tábula rasa, al contrario, diría que el hecho de tomar conciencia de que estamos en un mundo terminado nos obliga a proteger este mundo, que por tanto se convierte en patrimonio, en nuestra historia. Ello nos obliga a proteger mucho más, ciertamente, y se ha hecho así desde los años 70, desde la segunda mitad del siglo XX. Circunstancia muy interesante que sitúa al patrimonio, filosóficamente hablando, como algo diferente.

revista ph: ¿Algún otro trabajo que incida en sus nuevas perspectivas de lo patrimonial?

Me gustaría hablar de un proyecto que imagino para el Arco del Triunfo de París, un trabajo patrimonial que es un memorial. La idea es encontrarnos con una red subterránea, lo que llamo groundscape, como landscape. Esta historia trata sobre el paisaje del suelo, sobre una red bajo rasante que no sea autista, donde cada uno hace su tubo: el del metro, el del parking, las alcantarillas, la fibra óptica... La idea es desarrollar una reflexión sistémica sobre lo que afecta al subsuelo, y que toda esa red, ese sistema, se convierta de hecho en rizoma, en sistema enraizador de los edificios y la ciudad.
Por ello, el Arco del Triunfo es un ejemplo muy significativo. Porque hay metro, también hay pasos subterráneos para los coches que conectan los Campos Elíseos y la avenida de la Grande Armée. Eliminando los pasos, pues hay menos coches, se podría recuperar y transformar toda esta gran galería subterránea, abriéndola. La propuesta incluye un gran disco de vidrio para el Arco del Triunfo, abrir salas museales, salas para el memorial. Y obtener una vista desde abajo del Arco del Triunfo, dándole un valor simbólico más importante aún. Imagino por la tarde, cuando la luz entra, viene, emana de este disco de vidrio, cómo se percibirá algo casi mágico en este referente nacional.

Nos encontramos en este caso con un territorio de investigación del desarrollo de la ciudad, que está en tres dimensiones. No es ya un problema plano. Hay dos dimensiones, pero se está en un desarrollo de cuatro direcciones: hacia arriba, de una parte a otra en horizontal, y en profundidad. Por ello, para mí la ciudad se convierte en una sustancia que tiene espesores, dimensiones que no tenía en la época de los planes de Haussmann para París, o de Cerdà en Barcelona, la época maravillosa en que se podía diseñar la ciudad en dos dimensiones. Hoy estamos en otro momento.

revista ph: Determinados edificios suyos forman parte inequívoca del patrimonio contemporáneo. ¿Cómo interioriza usted esa consciencia y qué valor patrimonial destacaría?

La Biblioteca Nacional de Francia es patrimonio porque es un encargo público. Es muy importante su estatus, como Luxemburgo (Palacio Europeo de Justicia). El velódromo y la piscina olímpicos de Berlín son también en parte edificios públicos, donde hay una relación entre patrimonio y edificio. Son para la colectividad, una gran exigencia, pero también resulta bastante claro. Ahora es un poco más complicado, ahí es donde ahora está la dimensión del patrimonio, en algo importante que no solo es la conservación. Evidentemente, las gentes del patrimonio tienen que velar por la conservación, pero ello solo es un error, porque arquitectónicamente es insuficiente, porque hoy lo público no tiene dinero, necesita de lo privado. 


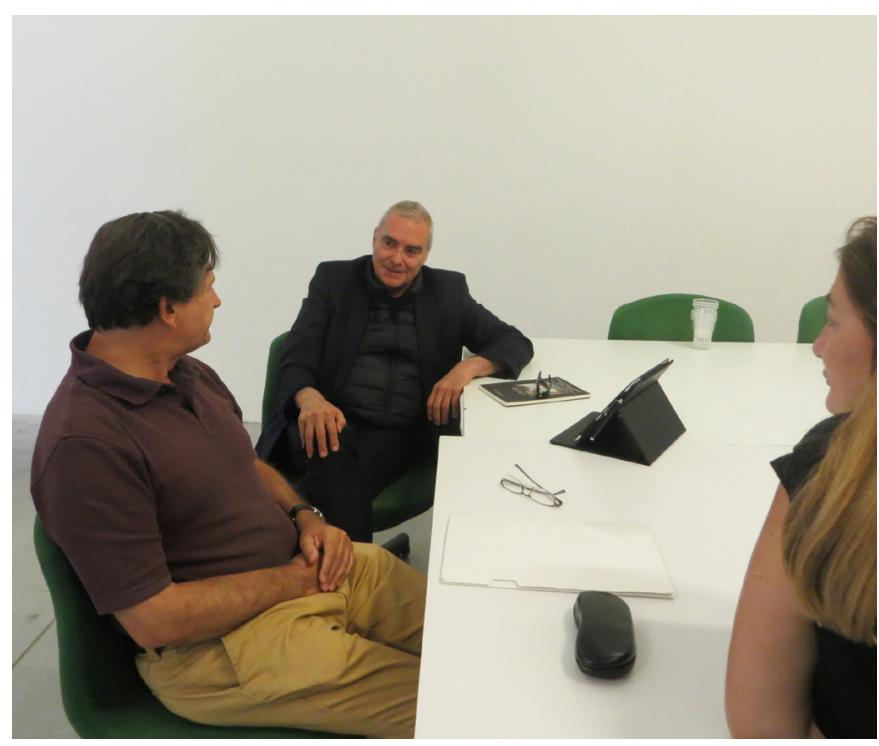

Durante la entrevista, con Eduardo Mosquera Adell y M. ${ }^{a}$ Teresa Pérez Cano foto Charlotte Jean

revista ph: ¿Cómo se expresa entonces lo público ante el patrimonio ahora, para usted?

En estos momentos el encargo público casi ha desaparecido, solo hay encargos privados. Pero no están solos, están ligados al ámbito público. Es decir, cuando se va a invertir en tal edificio, que va a ser pagado por el sector privado, lo público estará en el jurado del concurso. Y es lo público quien va a dar la autorización. La esfera de lo público está permanentemente en el proceso, no como con anterioridad en el liderazgo -porque ya no hay dinero- pero tiene el liderazgo político.

Por tanto, es ahí donde está la dimensión del patrimonio, algo muy importante. Porque lo público es bastante consciente de que va a construir un fragmento del futuro. Su posición y su mirada son diferentes. Hoy el político no es en absoluto consciente, no comprende que el sector privado va a realizar un edificio que responde a una necesidad, cierta, pero que no basta.

Como se suele decir, una puerta se cierra, una puerta se abre. Es evidente. Lo más interesante es que este encargo privado va a crear un edificio patrimonial. Puesto que con el tiempo el edificio va a revertir hacia lo público. Por ejemplo, el edificio de la Fundación Louis Vuitton, en
30 años pertenecerá a la ciudad. Y el edificio es patrimonial. Y está financiado privadamente al 100\%.

Hoy se construyen hospitales privados, con dinero privado. Se construyen estaciones, aeropuertos..., diferentes edificios o diferentes equipamientos se van a convertir en patrimoniales. De modo que eso es interesante. Y lo público, el encargo público, tiene una responsabilidad para el futuro, porque concierne al patrimonio. Y esta es su responsabilidad. Lo privado no puede tener esta responsabilidad, porque no representa al conjunto de los ciudadanos.

En definitiva, es más bien un ejercicio de diálogo. Si el político se posiciona, en relación a una visión patrimonial del encargo, el diálogo puede elevarse y situarse con lo privado. Lo que es muy interesante porque con lo público nos reencontramos con una posición colectiva, política. Es muy simple hoy día, por tanto: lo público concede el proyecto y se termina con la iniciativa privada, tenga o no cultura, construya o no construya patrimonio. Pero al final existe el compromiso con el patrimonio, porque lo público sí lo tiene intrínsecamente, porque es alguien electo, nos representan, es la democracia.

revista ph: La sede de su agencia de arquitectura se encuentra en un antiguo edificio industrial ¿Es casualidad...?

(Sonrisa) En realidad fue una oportunidad. Antes, pasé quince años en el Hotel industrial Jean-Baptiste Berlier. Esta sede de rue Bouvier tiene una buena imagen para los clientes. 